\title{
Editorial
}

Int Neurourol J 2012;16:101

http://dx.doi.org/10.5213/inj.2012.16.3.101

pISSN 2093-4777 • eISSN 2093-6931

\section{From Patch to Repair}

\section{Khae Hawn Kim}

Associate Editor

Department of Urology, Gachon University Gil Medical Center, Incheon, Korea Email: kimcho99@gilhospital.com

The anatomy of the urethral sphincter in both sexes has not been undisputed since it was first described more than 160 years ago. Although 18th and 19th century explanations of the urethral sphincter were most precise and thorough, contemporary textbooks lack details and include inaccuracies and ambiguous statements or illustrations $[1,2]$. There is currently a need to examine how much we know, or rather how much we don't know, about the anatomy of the urethral sphincter as a clinical and functional destination. What comes to mind when we think of urinary incontinence? Is it like the coronary artery in myocardial infarction, the Achilles tendon in the no passive plantar flexion, or the facial nerve (VII cranial nerve) of Bell's palsy? Most clinicians don't know much about urinary incontinence other than that its causes include the striated sphincter by hammock theory and intrinsic sphincter deficiency and that it leads to mid-urethral sling procedures. Furthermore, corrective urological surgery has been available for decades, including procedures to alleviate incontinence or anatomical defects of the pelvis after prostatectomy. In the 1990s, surgeons began offering procedures that promised the improved efficacy, aesthetics, and confidence associated with mid-urethral sling or other minimally invasive anti-incontinence surgeries. However, we should know more. We should become acquainted with the developmental anatomy of the urethral sphincter complex regarding continence mechanisms and the clinical nature of the urethral sphincter in both sexes. We should do so at least so that we can perform the anti-incontinence procedures on the basis of the mechanism causing urinary incontinence that is introduced in this issue [3]. This review not only points to the basic and clinical anatomy of the internal and the external sphincter but also emphasizes their clinical meaning: that continence is driven by the sphincter mechanism composed of the detrusor, trigone, and urethral muscles, each of different muscular origins, rather than by sphincter appearance itself.

\section{REFERENCES}

1. Yucel S, Baskin LS. An anatomical description of the male and female urethral sphincter complex. J Urol 2004;17:1890-7.

2. Koraitim MM. The male urethral sphincter complex revisited: an anatomical concept and its physiological correlate. J Urol 2008;179: 1683-9.

3. Jung J, Ahn HK, Huh Y. Clinical and functional anatomy of the urethral sphincter. Int Neurourol J 2012;16:102-6. 